11,19

\title{
Электропроводность и уравнения состояния $\beta$-ромбоэдрического бора в мегабарном диапазоне динамических давлений
}

\author{
(C) А.М. Молодец, А.А. Голышев, Д.В. Шахрай, В.В. Ким \\ Институт проблем химической фризики РАН, \\ Черноголовка, Россия \\ E-mail: molodets@icp.ac.ru
}

(Поступила в Редакцию 9 января 2017 г.)

Целью исследования являлось определение барической зависимости удельной электропроводности бора в условиях ступенчатого ударного сжатия мегабарного диапазона. Для достижения этой цели решены следующие задачи. Измерена электропроводность образцов бора в области динамических давлений, где существуют различные фазы высокого давления этого элемента. Построены уравнения состояния $\beta$-ромбоэдрического бора и аморфного бора в мегабарном диапазоне давлений. Рассчитаны термодинамические состояния бора в условиях выполненных экспериментов, что в комплексе с результатами измерений позволило определить изменение удельной электропроводности бора при сильном ступенчатом ударном сжатии в области динамических давлений до $110 \mathrm{GPa}$. Увеличение электропроводности поликристаллического бора в области мегабарных давлений истолковано как следствие перехода неметалл-металл.

Работа выполнена при поддержке Госкорпорации „Росатом“ в рамках контракта № Н.4х.44.9Б.16.1012 от 01.03.2016 г

DOI: 10.21883/FTT.2017.07.44603.001

\section{1. Введение}

Изучению теплофизических свойств конденсированных фаз бора в условиях штатного функционирования объектов атомной энергетики посвящена обширная научная литература. Наряду с этим необходимы сведения и о теплофизических свойствах бора в экстремальных условиях высоких динамических давлений, которые возникают при авариях или в импульсных ядерных энергетических установках в течение коротких, микросекундных времен. Поэтому анализ функционирования объектов ядерной энергетики в экстремальных условиях должен опираться на данные о физических свойствах материалов, в том числе бора, в этих условиях. Наряду с этим исследования физики бора при высоких давлениях не теряют своей актуальности и интенсивно ведутся на протяжении многих лет (см. работы [1-8] и ссылки в них). Таким образом, современные прикладные исследования теплофизических свойств бора в экстремальных условиях тесно соприкасаются с задачами фундаментальных исследований физики бора и его структурных превращений в диапазоне высоких динамических давлений.

В настоящее время экспериментально исследован ряд модификаций элементарного бора при высоких давлениях. Главной структурной единицей всех кристаллических решеток полиморфных модификаций бора является икосаэдр с двенадцатью атомами бора в вершинах и двадцатью треугольными гранями. При этом электрофизические и теплофизические свойства различных модификаций бора при высоких давлениях зачастую оказываются неожиданными. Например, орторомбическая модификация $\gamma$-В 28 представляет собой необычное ионное соединение, состоящее из одинаковых атомов [2]. В этой фазе бора возникает локализация электронов, что обусловливает ее низкую электропроводность.

Фазовая диаграмма бора содержит также область гипотетической металлической фазы высокого давления бора $\alpha$-B(Ga). Металлизация бора в области мегабарных давлений обусловлена разрушением двенадцатиатомных икосаэдров. Переход неметалл-металл был рассмотрен в работе [3], где обозначена граница области $\alpha-\mathrm{B}(\mathrm{Ga})$ при давлении выше $74 \mathrm{GPa}$. Однако в [2] отмечается, что, согласно расчетам, фаза $\gamma-\mathrm{B}_{28}$ оказывается устойчивой до более высоких давлений и соответственно граница металлизации бора из-за перехода $\gamma$ - $\mathrm{B}_{28} \rightarrow \alpha$-B(Ga) прогнозируется при $89 \mathrm{GPa}$.

Ранее в [4] было показано, что при комнатной температуре кристаллический $\beta$-ромбоэдрический бор переходит в аморфное состояние при давлении около $100 \mathrm{GPa}$, т.е. $\beta$-ромбоэдрический бор, оставаясь в метастабильном состоянии при высоких давлениях, в области существования фазы $\gamma$-В 28 становится нестабильным, но не переходит ни в фазу $\gamma-\mathrm{B}_{28}$, ни в фазу $\alpha-\mathrm{B}(\mathrm{Ga})$. $\mathrm{B}$ то же время нагрев образца $\beta$-бора в процессе сжатия до $2000 \mathrm{~K}$ приводит к превращению этой фазы в фазу $T-\mathrm{B}_{192}$ при $10 \mathrm{GPa}$ [5]. Таким образом, низкотемпературная аморфизация $\beta$-ромбоэдрического бора обусловлена кинетическими ограничениями и поэтому не исключает его переход в одну из кристаллических фаз $\left(\gamma-\mathrm{B}_{28}\right.$ или $\alpha$-B $(\mathrm{Ga})$ в области тысячеградусных температур и мегабарных давлений, когда будет преодолен энергетический барьер, разделяющий кристаллические фазы.

Некоторые модификации бора, в частности $\beta$-ромбоэдрический бор, оказываются метастабильными, что поз- 
воляет исследовать такие их свойства, как плотность, теплоемкость, продольную и поперечную скорость звука, модуль объемного сжатия, комнатную изотерму высокого давления, электропроводность и др. При нормальных условиях кристаллический и аморфный бор представляют собой полупроводники (см. работы [6-8] и ссылки в них). Изменение электропроводности бора с увеличением температуры подчиняется экспоненциальной зависимости. Экспоненциальная зависимость для $\beta$-ромбоэдрического бора сохраняется и при повышении давления до $10-30 \mathrm{GPa}$ [8].

Следует отметить, что экспериментальные исследования электропроводности бора выполнены либо в области высоких температур и сравнительно низких давлений (см. [8]), либо в области высоких давлений и низких температур [9]. Во втором случае была обнаружена сверхпроводимость поликристаллического $\beta$-ромбоэдрического бора [9]. Температура сверхпроводящего перехода бора составила $6 \mathrm{~K}$ при давлении $160 \mathrm{GPa}$ и увеличивалась с давлением до $11.2 \mathrm{~K}$ при $175 \mathrm{GPa}$. Таким образом, область одновременно высоких давлений и высоких температур остается малоисследованной. В связи с этим цель настоящей работы заключается в измерении электропроводности поликристаллического $\beta$-ромбоэдрического бора в области прогнозируемой металлизации бора при динамических давлениях до $110 \mathrm{GPa}$, при которых одновременно с повышением давления увеличивается и температура материала.

\section{2. Образцы}

Измерения электропроводности проведены для образцов поликристаллического и аморфного бора. Кристаллический бор (производитель Alfa Aeser) чистотой 99.4\% содержал следующие примеси: $\mathrm{Al}-0.017 \%$, $\mathrm{Fe}-0.05 \%, \mathrm{Mn}-0.01 \%, \mathrm{Si}-0.05 \%, \mathrm{C}-0.292 \%$, $\mathrm{N}-0.001 \%, \mathrm{O}-0.076 \%$. Образцы для измерений изготавливались из цельного куска поликристаллического бора путем шлифования на алмазном инструменте и представляли собой пластинки шириной $a_{0} \sim 3 \mathrm{~mm}$ и толщиной $b_{0} \sim 1 \mathrm{~mm}$. На широкой стороне пластинки размещались полоски (тоководы) из медной фольги $(0.03 \mathrm{~mm})$ на расстоянии $L_{0} \sim 4 \mathrm{~mm}$ друг от друга. Начальная плотность образцов кристаллического бора была равна $2.235(5) \mathrm{g} / \mathrm{cm}^{3}$. Начальная удельная электропроводность образцов составляла $\sigma_{0} \sim 10^{-5}(\Omega \cdot \mathrm{cm})^{-1}$.

Аморфный бор отечественной марки Б-99В имел чистоту $99 \%$ и первоначально представлял собой порошок с размером частиц 20-50 $\mu \mathrm{m}$. Из порошка изготовлялись образцы диаметром $10.0 \mathrm{~mm}$ и толщиной $b_{0} \sim 1.0 \mathrm{~mm}$. Начальная плотность образцов аморфного бора составляла величину $\sim 1.0 \mathrm{~g} / \mathrm{cm}^{3}$. На одну из плоскостей диска накладывались полоски (тоководы) из медной фольги $(0.03 \mathrm{~mm})$ на расстоянии $L_{0} \sim 4 \mathrm{~mm}$ друг от друга.
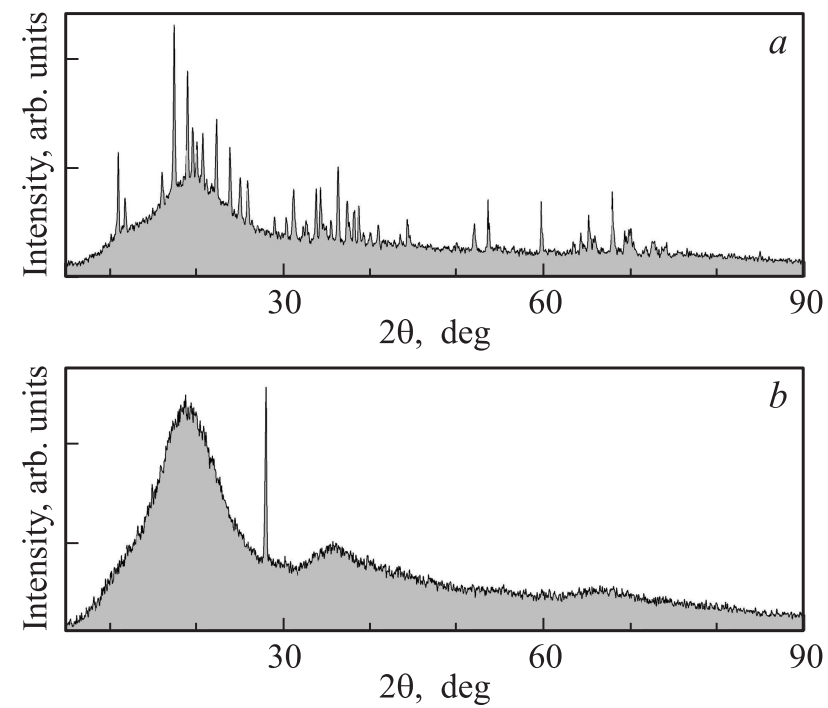

Рис. 1. Дифрактограммы образцов поликристаллического $\beta$-ромбоэдрического бора $(a)$ и аморфного бора $(b)$ в начальном состоянии.

На рис. 1, a показана дифрактограмма поликристаллического бора в исходном состоянии с применением кюветы из плавленого кварца, которая не содержит узких пиков, характерных для кристалла. Поэтому все интенсивные пики этой дифрактограммы относятся к исследуемому образцу. Местоположение и относительная интенсивность этих пиков свидетельствуют о том, что материал образца представлял собой $\beta$-ромбоэдрический бор. На рис. $1, b$ показана дифрактограмма аморфного бора, которая содержит три гало и пик в области $30^{\circ}$. Этот пик аналогично [6] обусловлен примесью $\mathrm{B}(\mathrm{OH})_{3}$.

\section{3. Схема измерения} электропроводности образцов бора
в течение микросекундных времен
ступенчатого ударного сжатия

На рис. 2 показана схема экспериментов по измерению электросопротивления образцов бора при ступенчатом ударном нагружении. На рис. 2 изображен образец 1 , фронтальная плоскость которого располагается перпендикулярно оси симметрии экспериментальной сборки. В этой же плоскости располагается манганиновый датчик давления 2 с начальной проводимостью $\sigma_{0 m} \sim 0.6 \Omega^{-1}$. Датчик 2 подсоединен параллельно образцу с помощью медных тоководов 3 . При измерении электропроводности образца $S$ во время $t$ ступенчатого ударного сжатия (профилей электропроводности $S(t))$ согласно [10] датчик 2 играет роль шунта, а электропроводность образца находится как разница между электропроводностью параллельного соединения образец 1 -шунт 2 и электропроводностью шунта-датчика 2. При этом шунт 2 располагался на 


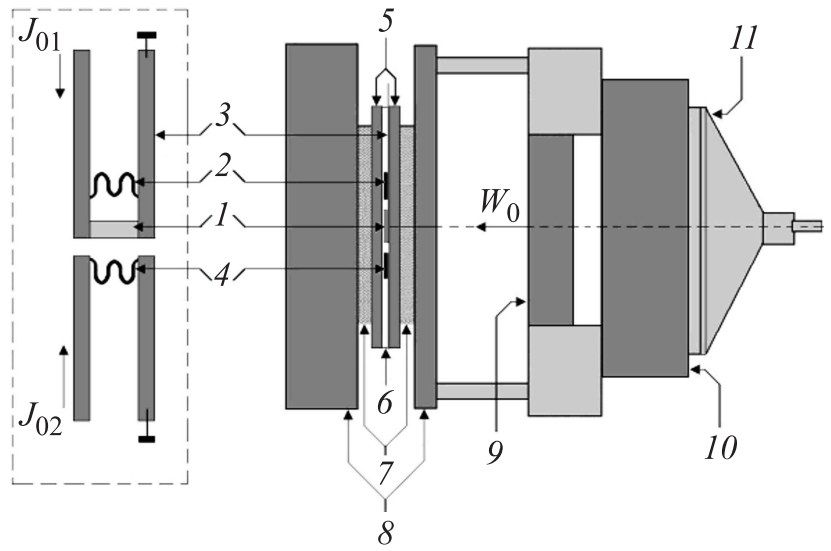

Рис. 2. Экспериментальная схема регистрации электросопротивления образцов бора при ступенчатом ударном сжатии. $1-4$ - измерительная ячейка, 5, 6 - тефлоновые пленки, 7, 8 - ударные наковальни, 9 - металлический (алюминий или сталь $12 \mathrm{X} 18 \mathrm{H} 10 \mathrm{~T})$ ударник, 10 - заряд взрывчатого материала, 11 - генератор плоской детонационной волны.

минимальном ( $1 \mathrm{~mm})$ расстоянии от образца. Согласно [10], такая схема регистрации позволяет свести к минимуму связанные с индуктивностью паразитные сигналы.

В качестве профилей электропроводности шунта использовалась электропроводность манганинового датчика 4 , расположенного симметрично тождественному датчику 2. Показания датчика 4 использовались также для фиксации времени прихода на образец волн сжатия при реверберации ударных волн в измерительной ячейке. Образец 1 и датчики 2,4 находились в одной и той же изолирующей среде. Эта среда представляла собой пленки 5 толщиной $0.5 \mathrm{~mm}$ и 6 толщиной $1.0 \mathrm{~mm}$ из фторопласта Ф-4 между которыми находился слой вакуумной смазки толщиной $\sim 0.1 \mathrm{~mm}$. Электрические свойства изолирующей среды при высоких динамических давлениях представлены в [11].

Слои 5 и 6 из материала с малой акустической жесткостью, содержащие образец и датчики, располагались между двумя жесткими (вольфрамовыми) пластинами 7, к каждой из которых примыкала стальная (сталь 12Х18Н10Т) пластина промежуточной жесткости 8. Сочетание динамических жесткостей материалов пластин 5-8 обеспечивало режим ступенчатого ударного нагружения исследуемого образца 1 и датчиков 2 и 4 .

Во время эксперимента по тоководам 3 из медной фольги толщиной $25 \mu \mathrm{m}$ пропускались постоянные токи величиной $J_{01}=J_{02}=10 \mathrm{~A}$ от двух независимых импульсных источников. С помощью высокоскоростного осциллографа регистрировались профили падения напряжения на зашунтированном образце $1-2$ и на датчике 4 в зависимости от времени. Поскольку напряжение обратно пропорционально проводимости, оказывается возможным определить проводимость образца 1 как разность проводимостей параллельного соединения
$1 / R_{\mathrm{B}+\text { shunt }}$ и датчика $1 / R_{\text {shunt. }}$ При этом возможное паразитное шунтирование образца изолирующей средой, будучи в обоих случаях одинаковым, оказывается исключенным.

Таким образом, измерительная ячейка на схеме, показанной на рис. 2, позволяет регистрировать изменения электропроводности от первоначально непроводящего состояния до значений электропроводности, сравнимой с электропроводностью шунта 2. С помощью величин электросопротивления $R_{\mathrm{B}+\text { shunt }}$ и $R_{\text {shunt }}$ в одни и те же моменты времени рассчитываются экспериментальные значения электропроводности $S$ образца бора в эти моменты времени как

$$
S=\frac{1}{R_{\mathrm{B}+\text { shunt }}}-\frac{1}{R_{\text {shunt }}} .
$$

Было проведено две серии экспериментов: первая - с максимальным давлением ступенчатого ударного сжатия $110 \mathrm{GPa}$ при скоростях стального ударника $2.6(1) \mathrm{km} / \mathrm{s}$, вторая - с максимальным давлением $45 \mathrm{GPa}$ при скоростях алюминиевого ударника $2.2(1) \mathrm{km} / \mathrm{s}$. На рис. 3 показаны типичные осциллограммы единичного эксперимента первой серии с записью профиля электросопротивления шунта $(a)$, профиля электросопротивления зашунтированного образца бора $(b)$ и профиля электропроводности образца боpa $(c)$, вычисленного по формуле (1). При этом каждый эксперимент моделировался в рамках одномерного гидрокода, опирающегося на разработанные уравнения состояния. Техника построения уравнений состояния и их параметры для поликристаллического и аморфного бора представлены в следующем разделе.

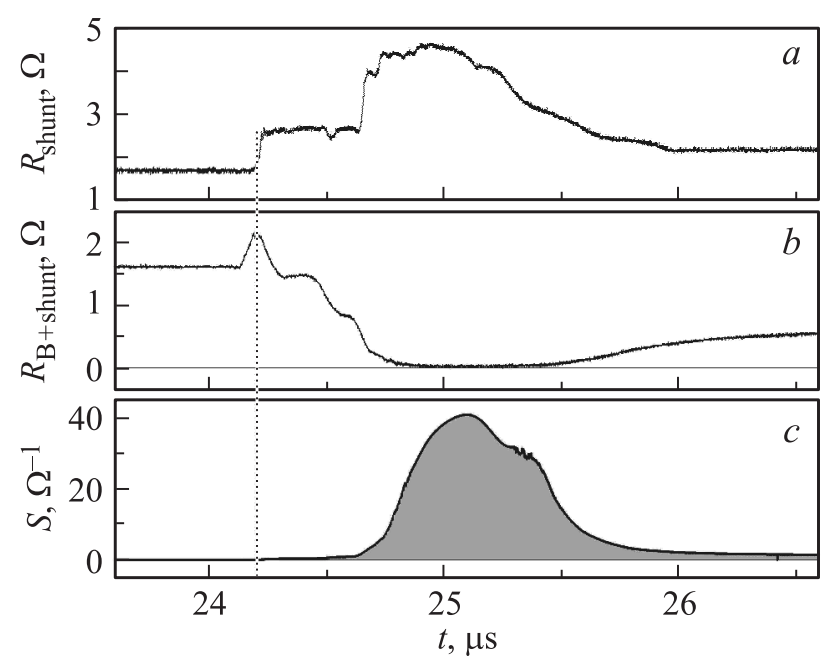

Рис. 3. Первичные экспериментальные осциллограммы, полученные при измерении профиля электропроводности $S(t)$ поликристаллического бора в течение времени $t$ ступенчатого ударного сжатия до $110 \mathrm{GPa} . a-$ изменение электросопротивления шунта, $b-$ изменение электросопротивления параллельного соединения шунта и образца бора, $c$ - электропроводность образца поликристаллического бора. Пунктирной вертикальной линией отмечен общий момент времени. 
Параметры для свободной энергии (2) $\beta$-ромбоэдрического бора и аморфного бора

\begin{tabular}{c|c|c|c|c|c|c|c|c|c}
\hline Материал & $\begin{array}{c}M, \\
\mathrm{~g} / \mathrm{mol}\end{array}$ & $\begin{array}{c}V_{0}, \\
\mathrm{~cm}^{3} / \mathrm{mol}\end{array}$ & $\begin{array}{c}v_{0}, \\
\mathrm{~cm}^{3} / \mathrm{mol}\end{array}$ & $\begin{array}{c}\Theta_{0}, \\
\mathrm{~K}\end{array}$ & $\begin{array}{c}v_{x}, \\
\mathrm{~cm}^{3} / \mathrm{mol}\end{array}$ & $\begin{array}{c}C_{1}, \\
\mathrm{GPa}\end{array}$ & $\begin{array}{c}C_{2}, \\
\mathrm{GPa}\end{array}$ & $\begin{array}{c}C_{3}, \\
\mathrm{~kJ} / \mathrm{g}\end{array}$ & $\begin{array}{c}\beta_{0}, \\
\mathrm{~mJ} / \mathrm{mol} \cdot \mathrm{K}^{2}\end{array}$ \\
\hline $\begin{array}{c}\beta \text {-бор } \\
\text { Аморфный бор }\end{array}$ & 10.81 & 4.6336 & 74.136 & 937.5 & 27.801 & -20.505 & 357.903 & -589.953 & 1.38 \\
& 4.6659 & 74.655 & 937.5 & 14.086 & -96.659 & 1984.032 & -1326.922 & 1.38
\end{tabular}

\section{4. Уравнения состояния бора и моделирование термодинамического состояния образца во время эксперимента}

4.1. Свободная энергия твердого тела. Уравнения состояния для поликристаллического и аморфного бора рассчитывались на основе полуэмпирического выражения для свободной энергии всесторонне сжатого изотропного твердого тела $\Phi=\Phi(V, T)$ в виде суммы фононной $F=F(V, T)$ и электронной $F_{e}=F_{e}(V, T)$ составляющих

$$
\Phi=F(V, T)+F_{e}(V, T) .
$$

Фононная составляющая свободной энергии всесторонне сжатого изотропного твердого тела, базирующаяся на модели эйнштейновских осцилляторов, представлялась в виде

$$
F=3 R\left[\frac{\Theta}{2}+T \ln \left(1-\exp \left(-\frac{\Theta}{T}\right)\right)\right]+E_{x},
$$

где $R$ - удельная газовая постоянная, $V-$ удельный объем материала, $T$ - его температура, $\Theta=\Theta(V)-$ объемная зависимость характеристической температуры, определяемая, согласно [12,13], как

$$
\begin{gathered}
\Theta=\Theta_{0}\left(\frac{v_{0}-V}{v_{0}-V_{0}}\right)^{2}\left(\frac{V_{0}}{V}\right)^{2 / 3} . \\
v_{0}=V_{0}\left(1+\frac{2}{\gamma_{0}-2 / 3}\right) .
\end{gathered}
$$

В (2)-(5) $\Theta_{0}=\Theta\left(V_{0}\right)$ - начальная характеристическая температура, $\gamma_{0}=\gamma\left(V_{0}\right)$ - термодинамический коэффициент Грюнайзена, $V_{0}$ - начальный удельный объем. Под начальными условиями $\left(V_{0}, T_{0}, P_{0}\right)$ подразумеваются нормальные условия с начальной температурой $T_{0}$ и начальным давлением $P_{0}$.

Объемная зависимость потенциальной энергии $E_{x}=E_{x}(V)$ также взята из $[12,13]$

$$
\begin{gathered}
E_{x}=-v_{x}\left(C_{1} H_{x}+C_{2} x\right)+C_{3} \\
H_{x}=9\left(\frac{1}{10} x^{-2 / 3}+2 x^{1 / 3}+\frac{3}{2} x^{4 / 3}-\frac{1}{7} x^{7 / 3}+\frac{1}{70} x^{10 / 3}\right) \\
x=\frac{V}{v_{x}} .
\end{gathered}
$$

$\mathrm{B}(6)-(8) v_{x}-$ подгоночный параметр, первое приближение которого есть $v_{0}$. Параметры $C_{1}, C_{2}, C_{3}-$ константы, выражающиеся через справочные свойства материала (плотность, модуль объемного сжатия, характеристическая температура, коэффициент Грюнайзена при нормальных условиях) и подгоночный параметр $v_{x}$.

Электронная составляющая $F_{e}$ записывалась согласно литературным данным [14]

$$
F_{e}=-\frac{1}{2} \beta_{0} T^{2}\left(\frac{V}{V_{0}}\right)^{\gamma_{e}},
$$

где $\gamma_{e}-$ электронный коэффициент Грюнайзена, $\gamma_{e}=1 / 2, V_{0}-$ начальный удельный объем, $\beta_{0}-$ коэффициент электронной теплоемкости, рассматриваемый здесь как второй подгоночный коэффициент в (2).

4.2. Термическое и калорическое уравнения состояния бора. Термическое и калорическое уравнения состояния находились с помощью частных производных (2) согласно общим термодинамическим соотношениям. Калорическое уравнение состояния (зависимость внутренней энергии $E$ от объема и температуры $T$ ) определяется частной производной свободной энергии по температуре

$$
E=\Phi-T(\partial \Phi / \partial T) .
$$

Аналогично термическое уравнение состояния (зависимость давления $P$ от объема и температуры $T$ ) $P=P(V, T)$ определяется как

$$
P=-\partial \Phi / \partial V \text {. }
$$

Теплоемкость материала при постоянном давлении $C_{p}$ рассчитывалась как

$$
C_{p}=-T\left(\frac{\partial^{2} \Phi}{\partial T^{2}}+\frac{(\partial P / \partial T)^{2}}{\partial P / \partial V}\right) .
$$

Значения коэффициентов в (2) и, следовательно, в $(10)-(12)$ для $\beta$-ромбоэдрического бора и аморфного бора вместе с молярной массой $M$ приведены в таблице.

Рис. 4,a демонстрирует согласие расчетной $P=P\left(V, T_{0}\right)$ и экспериментальной комнатных изотерм высокого давления поликристаллического бора в диапазоне до $\sim 100 \mathrm{GPa}$. Как видно, различие между расчетной и экспериментальной изотермами не превышает разброса экспериментальных данных, который находится на уровне $2 \%$.

Рис. $4, b$ демонстрирует согласие расчетных и экспериментальных свойств поликристаллического бора на 

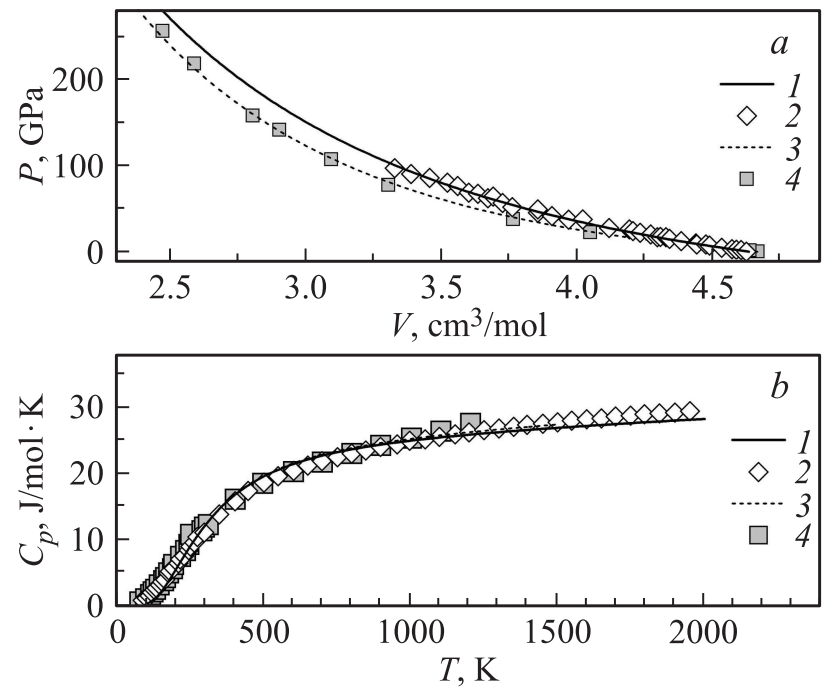

Рис. 4. Комнатная изотерма (зависимость давления $P$ от объема $V$ при температуре $300 \mathrm{~K})$ высокого давления $(a)$ и зависимость теплоемкости при постоянном (атмосферном) давлении $C_{p}$ от температуры $T(b)$ для $\beta$-ромбоэдрического бора и аморфного бора. a) $1-$ расчет $P=P\left(V, T_{0}\right)$ для поликристаллического бора с помощью (11), 2 - эксперимент [4], 3 - расчет $P=P\left(V, T_{0}\right)$ для аморфного бора с помощью (11), 4 - теоретические данные [15] для аморфного бора. b) 1 - расчет для поликристаллического бора с помощью (12), 2 - эксперимент [16] для поликристаллического бора, 3 - расчет для аморфного бора, 4 - эксперимент для аморфного бора, представленный в [17].

примере температурной зависимости теплоемкости. Как видно, различие между экспериментальными данными и расчетными значениями теплоемкости не превышает 5\% в диапазоне температур 300-1800 K.

На рис. 4 представлены также данные для аморфного бора. Так, на рис. 4, $a$ показано согласие расчета комнатной изотермы $P=P\left(V, T_{0}\right)$ аморфного бора с помощью (11) и теоретической изотермы [15] аморфного бора до $220 \mathrm{GPa}$. Видно, что, как и в случае кристаллического бора, здесь различие между полуэмпирическим расчетом и теоретическими результатами также не превышает разброса опорных данных, который находится на уровне $2 \%$. Из рис. $4, b$ видно согласие рассчитанных и измеренных свойств аморфного бора на примере температурной зависимости теплоемкости. Здесь различие между экспериментальными данными и расчетными значениями теплоемкости также невелико и не превышает 5\% в диапазоне температур 200-1200 K.

4.3. Термодинамическое состояние и электропроводность бора во время эксперимента. Математическое моделирование эксперимента по измерению электропроводности осуществлялось в рамках гидрокода [18]. Этот гидрокод позволяет рассчитывать профили термодинамических переменных одномерного ступенчатого сжатия для заданной лагранжевой частицы с учетом ревербераций волн сжатия и разгрузки во всех пластинах сборки (рис. 2) при условии, что уравнения состояния бора и всех сопутствующих материалов этой сборки определены в форме (10) и (11). Для нержавеющей стали и алюминия использовались уравнения состояния из работ [13] и [19] соответственно. Для бора использовались уравнения состояния, построенные в предыдущем подразделе. Затем расчетные профили давления, температуры и объема соотносились с экспериментальным профилем электропроводности образца, что позволяло рассчитать удельную электропроводность бора вдоль фазовой траектории динамического нагружения.

На рис. 5 представлен способ соотнесения экспериментального профиля электропроводности с расчетными профилями давления и температуры. Здесь значения $S_{i}$, $P_{i}, T_{i}$ в точках $i(i=1,2,3, \ldots, n)$ определяют $n$ значений электропроводности образца бора $S_{i}=S\left(P_{i}, T_{i}\right)$.

Дополняя полученную экспериментально-расчетную информацию расчетными значениями объема $V_{i}$ в эти же моменты времени, можно найти зависимость удельной электропроводности $\sigma$ бора вдоль фазовой траектории ступенчатого ударного сжатия и последующей разгрузки в виде $\sigma_{i}=\sigma\left(P_{i}, T_{i}, V_{i}\right)$. Действительно, предполагая, что при плоском одномерном ступенчатом ударном сжатии объем образца изменяется только за счет изменения толщины образа $b_{0}$, можно записать

$$
\lg \sigma_{i}=\lg S_{i}+\lg \frac{L_{0}}{a_{0} b_{0}}+\lg \frac{V_{0}}{V_{i}} .
$$

Вычисления по формуле (13) для двух серий опытов представлены на рис. 6. Для каждой серии наблюдалась воспроизводимая форма профилей осциллограмм электросопротивления зашунтированного образца бора.
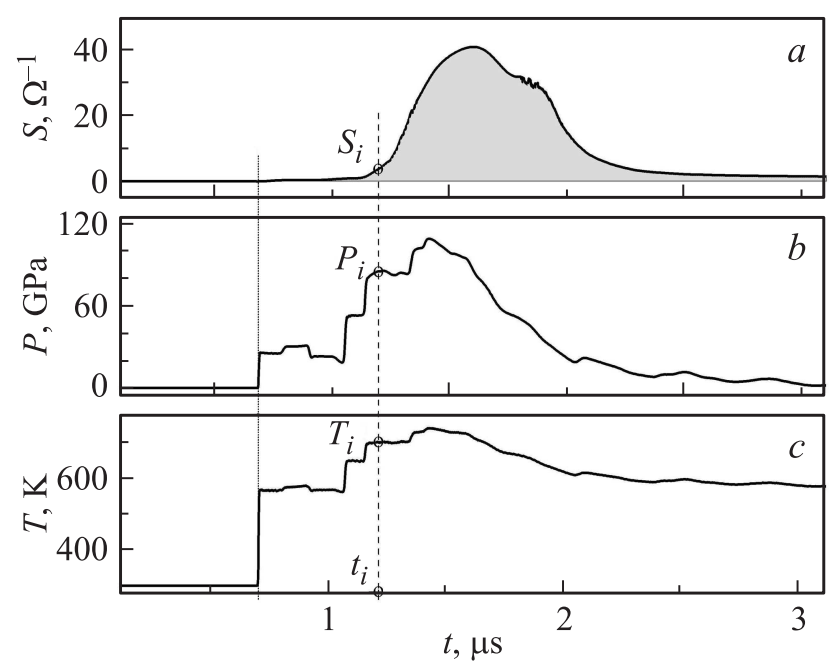

Рис. 5. Соотнесение измеренной электропроводности образца бора с его давлением и температурой при ступенчатом ударном сжатии до $110 \mathrm{GPa} . a-$ экспериментальный профиль (см. рис. 3,c) электропроводности образца поликристаллического бора, $b$ - расчетный профиль давления в образце, $c$ - расчетный профиль температуры образца. 


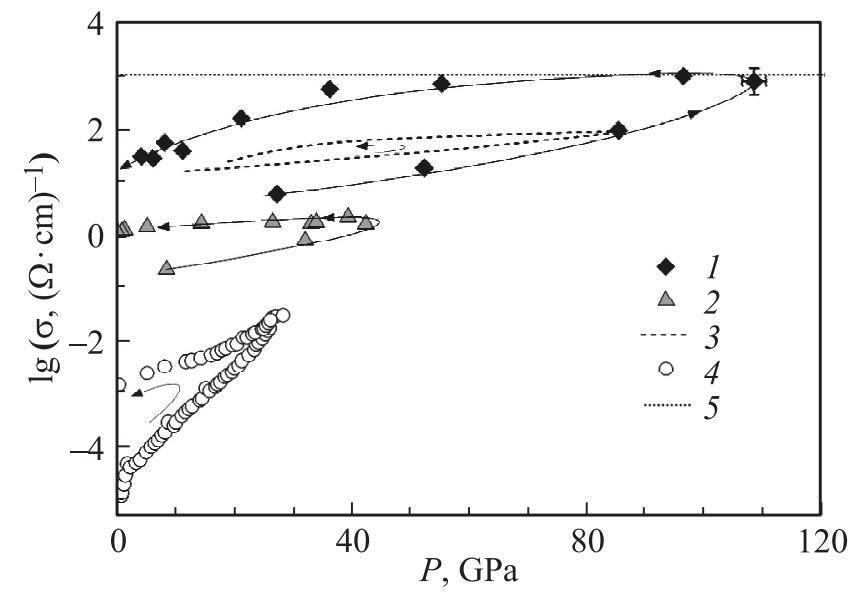

Рис. 6. Зависимость удельной электропроводности $\sigma$ от давления $P$ в цикле сжатие-разгрузка вдоль фазовых траекторий ступенчатого ударного сжатия и последующей разгрузки. 1,2 - поликристаллический бор при сжатии до 110 и $45 \mathrm{GPa}$ соответственно, 3 - аморфный бор, 4 - поликристаллический бор в условиях высоких статических давлений из работы [8], 5 - минимальная металлическая проводимость Иоффе-Регеля $\sigma_{m}=10^{3}(\Omega \cdot \mathrm{cm})^{-1}$. Стрелки указывают направление изменения давления.

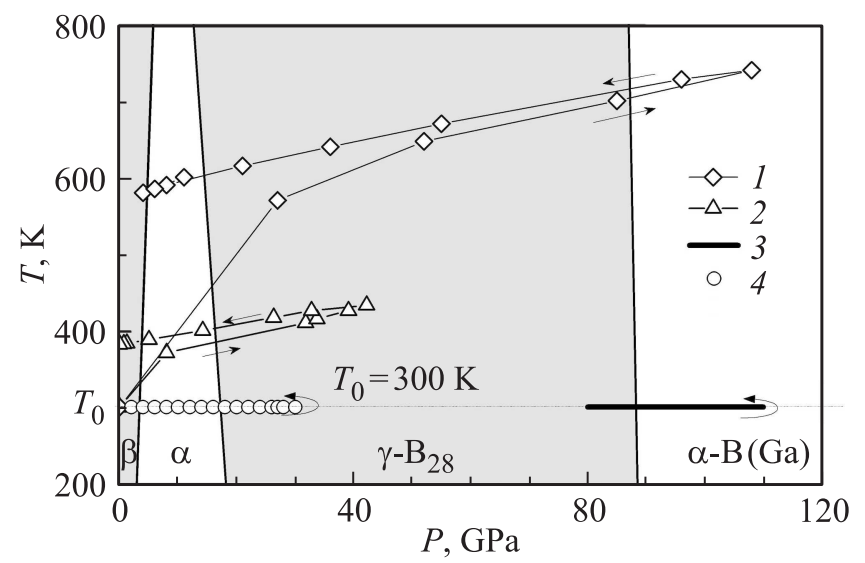

Рис. 7. Зависимость температуры $T$ от давления $P$ вдоль фазовых траекторий сжатия поликристаллического бора на фазовой диаграмме бора из работы [2]. 1,2 - фазовые траектории ступенчатого ударного сжатия до 110 и $45 \mathrm{GPa}$ соответственно, 3 и $4-$ фазовые траектории изотермического сжатия из работ [8] и [4] соответственно. Стрелки указывают направление изменения давления.

Связь между давлением и температурой вдоль фазовой траектории ступенчатого ударного сжатия и последующей разгрузки представлена на рис. 7.

Обсудим точность определения удельной электропроводности, проведенного в настоящей работе. Для этого оценим погрешность слагаемых (13) с помощью трех коэффициентов $p, q, m$, отражающих максимальную погрешность каждого из этих слагаемых

$$
\lg \sigma_{i \max }=\lg \left(p S_{i}\right)+\lg \left(q \frac{L_{0}}{a_{0} b_{0}}\right)+\lg \left(\frac{V_{0}}{V_{i}}\right)^{m} .
$$

Коэффициент $p$ отражает погрешность измерения электросопротивления шунта и параллельного соединения шунт-образец, которая составляет $\sim 20 \%$. Поэтому его максимальное значение равно 1.2. Величина коэффициента $q$ определяется отклонением реальной геометрии образца от параллелепипеда и искривлением линий тока между тоководами в реальном образце. Наибольшее значение этого коэффициента составляет $q=1+\frac{2 b_{0}}{L_{0}}$, где $b_{0}$ - толщина образца, $L_{0}-$ расстояние между тоководами. Величина коэффициента $m$ отражает отличие гидростатического сжатия образца от одномерного сжатия в направлении его толщины. В первом случае величина $m$ составит $m=1 / 3$, во втором $m=1$. Таким образом, оценка максимальной погрешности $\lg \sigma_{i}$ составит

$$
\lg \sigma_{i \max }=\lg \left(S_{i}\right)+\lg \left(\frac{L_{0}}{a_{0} b_{0}}\right)+m \lg \left(\frac{V_{0}}{V_{i}}\right)+\lg (p q) .
$$

Оценка погрешности в величине логарифма удельной электропроводности по формуле (15) составляет 10\% и совпадает с величиной максимального разброса данных тождественных экспериментов. Как отмечалось выше, точность расчета давления и температуры находится в пределах 2\% по давлению и 5\% по температуре. Кроме того, в погрешность расчетов входит неопределенность скорости ударника, которая известна с точностью $3 \%$. Суммарная оценка точности полученных результатов по удельной электропроводности бора показана крестиком на рис. 6.

\section{5. Обсуждение результатов}

Как видно из рис. 6, электропроводность поликристаллического и аморфного бора при ступенчатом ударном сжатии изменяется от практически нулевых начальных значений до величин порядка $10-100(\Omega \cdot \mathrm{cm})^{-1}$. При этом кривые изменения удельной электропроводности 1 и 2 поликристаллического бора при ступенчатом ударном сжатии в обеих сериях (до 110 и $45 \mathrm{GPa}$ ), а также кривая 3 для аморфного бора обладают гистерезисом. В этом отношении полученный результат согласуется с гистерезисом электропроводности поликристаллического бора в условиях высоких статических давлений из работы [8] (см. кривую 4).

Отметим, что при качественном подобии кривых 1 и 2 электропроводность ударно-сжатых образцов поликристаллического бора в первой серии экспериментов оказывается на два-три порядка больше, чем во второй. Из рис. 7 видно, что температуры в первой серии экспериментов были примерно в 2 раза больше, чем в серии экспериментов с максимальным давлением $45 \mathrm{GPa}$. Если различие электропроводностей на два порядка обусловлено главным образом температурой, то можно предполагать характерную для полупроводников экспоненциальную температурную зависимость проводимо- 
сти ударно-сжатого изначально поликристаллического $\beta$-ромбоэдрического бора.

Обсудим подробнее результаты второй серии экспериментов. Как видно, траектория 2 на рис. 7 пересекает две линии равновесия $\beta \leftrightarrow \alpha$ и $\alpha \leftrightarrow \gamma$-В 28 . Поэтому можно было ожидать скачки электропроводности в точках пересечения траекторий с линиями равновесия фаз. Однако в пределах точности измерения скачкообразных изменений удельной электропроводности не зафиксировано. Отметим также, что траектория 2 на рис. 7 лежит вблизи траектории 3 из работы [8], вдоль которой также не замечено скачков электропроводности. При этом траектория 3 расположена вдали от области аморфизации бора 4 из работы [4]. Поэтому можно полагать, что и при ступенчатом ударном сжатии до $45 \mathrm{GPa}$ начальная фаза $\beta$-ромбоэдрического бора остается в кристаллическом метастабильном состоянии как при сжатии, так и при разгрузке.

Обсудим эксперименты с образцами поликристаллического и аморфного бора при высоких давлениях. Заметим, что траектория 1 на рис. 7 проходит через область давлений 4, где в [4] экспериментально обнаружена аморфизация кристаллических фаз бора. В связи с этим можно было ожидать, что по аналогии c [4] аморфизация бора будет иметь место и в наших экспериментах. Поэтому если электропроводность ударно-сжатого изначально аморфного бора окажется близкой к электропроводности ударно-сжатого, но изначально кристаллического бора, то этот результат будет свидетельствовать в пользу предположения об аморфизации кристаллического бора при ударном сжатии. Эти эксперименты были проведены, соответствующие экспериментально-расчетные значения удельной электропроводности представлены на рис. 6 кривой 3 . Как видно, при давлениях $90 \mathrm{GPa}$ удельные электропроводности изначально поликристаллического (1) и аморфного (3) бора близки. Этот факт может быть истолкован в логике сделанного выше предположения: при ступенчатом ударном сжатии поликристаллического бора в области 90-110 GPa происходит его по крайней мере частичная аморфизация. В связи с этим оправдано сопоставление максимальных значений удельной электропроводности бора при ступенчатом ударном сжатии вблизи $110 \mathrm{GPa}$ с величиной минимальной металлической проводимости в неупорядоченных средах.

Действительно, как известно (см. [20]), для неупорядоченных сред минимальная металлическая проводимость Иоффе-Регеля $\sigma_{m}$ оценивается величиной $\sigma_{m}=$ $=1000-5000(\Omega \cdot \mathrm{cm})^{-1}$. Значение $\sigma_{m}=1000(\Omega \cdot \mathrm{cm})^{-1}$ отмечено пунктирной линией 5 на рис. 6. Из этого же рисунка видно, что величина электропроводности ударно-сжимаемого бора вдоль фазовой траектории 1 при увеличении давления до $110 \mathrm{GPa}$ повышается и оказывается на уровне $\sigma_{m}$. Кроме того, линии 1 и 5 пересекаются и при разгрузке в области давлений $\sim 60-80 \mathrm{GPa}$. Такое взаимное расположение линий 1 и 5 на рис. 6 позволяет дать следующую интерпретацию полученных экспериментальных данных. При ступенчатом ударном сжатии бора в области давлений $\sim 100 \mathrm{GPa}$ происходит переход неметалл(полупроводник) $\rightarrow$ металл, а при последующей разгрузке в области давлений $\sim 60-80 \mathrm{GPa}$ имеет место обратный переход металл $\rightarrow$ неметалл(полупроводник).

\section{6. Заключение}

Проведены эксперименты по исследованию электрофизических свойств $\beta$-ромбоэдрического бора и аморфного бора при высоких давлениях в условиях ступенчатого ударного сжатия.

Разработаны уравнения состояния исследуемых материалов, позволяющие рассчитывать их теплофизические свойства в экстремальных условиях сильного ударного сжатия, и выполнено математическое моделирование проведенных экспериментов.

Получены экспериментально-расчетные данные об удельной электропроводности $\beta$-ромбоэдрического бора в диапазоне давлений до $110 \mathrm{GPa}$, температур до $800 \mathrm{~K}$ и сжатий до 1.4 .

Показано, что при сильном ступенчатом ударном сжатии удельная электропроводность $\beta$-ромбоэдрического бора увеличивается от $10^{-5}$ до $10^{+3}(\Omega \cdot \mathrm{cm})^{-1}$. Увеличение электропроводности поликристаллического бора в области $100 \mathrm{GPa}$ истолковано как следствие перехода неметалл-металл.

Показано, что удельная электропроводность $\beta$-ромбоэдрического бора в цикле ступенчатое ударное сжатиеразгрузка обладает гистерезисом.

Обосновано предположение об аморфизации поликристаллического $\beta$-ромбоэдрического бора при ударном сжатии.

\section{Список литературы}

[1] R.H. Wentorf, Jr. Science 147, 3653, 49 (1965).

[2] A.R. Oganov, J. Chen, C. Gatti, Y.Z. Ma, Y.M. Ma, C.W. Glass, Z.X. Liu, T. Yu, O.O. Kurakevych, V.L. Solozhenko. Nature 457, 863 (2009).

[3] U. Häussermann, S.I. Simak, R. Ahuja, B. Johansson. Phys. Rev. Lett. 90, 6, 065701 (2003).

[4] D.N. Sanz, P. Loubeyre, M. Mezouar. Phys. Rev. Lett. 89, 24, 245501 (2002).

[5] Y. Ma, C.T. Prewitt, G. Zou, H.K. Mao, R. J. Hemley. Phys. Rev. B 67, 174116 (2003).

[6] E.A. Ekimov, V.A. Sidorov, R.A. Sadykov, E.L. Gromnitskaya, N.F. Borovikov. High Press. Res. 27, 1, 179 (2007).

[7] О.А. Гудаев, В.К. Малиновский. ФТТ 44, 5, 805 (2002).

[8] D. Zhang, Ch. Gao, Y. Ma, Ch. He, X. Huang, A. Hao, C. Yu, Y. Li, J. Liu, G. Peng, D. Li, H. Liu, G. Zou. J. Phys.: Condens. Matter 19, 425216 (2007).

[9] M.I. Eremets, V.V. Struzhkin, H.K. Mao, R.J. Hemley. Science 293, 5528, 272 (2001).

[10] С.С. Набатов, А.Н. Дрёмин, В.И. Постнов, В.В. Якушев. Письма в ЖЭТФ 29, 7, 407 (1978). 
[11] А.А. Голышев, А.М. Молодец. Физика горения и взрыва 49, 2, 106 (2013).

[12] А.М. Молодец. ЖЭТФ 107, 3, 824 (1995).

[13] А.М. Молодец. ФТТ 57, 10, 1992 (2015).

[14] Л.В. Альтшулер, С.Б. Кормер, А.А. Баканова, Р.Ф. Трунин. ЖЭТФ 38, 3, 790 (1960).

[15] B. Siberchicot, J. Clérouin. Solid State Phenom. 172-174, 1220 (2011).

[16] V.L. Solozhenko, O.O. Kurakevych. Sci. Rep. 3, 2351 (2013).

[17] A. Masago, K. Shirai, H. Katayama-Yoshida. Phys. Rev. B 73, 104102 (2006)

[18] В.В. Ким, А.А. Голышев, Д.В. Шахрай, А.М. Молодец. В сб.: Тр. ХI Междунар. конф. „Забабахинские научные чтения“. Снежинск (2012); http://www.vniitf.ru/images/zst/2012/s6/6-24.pdf

[19] А.М. Молодец. ФТТ 56, 11, 2162 (2014).

[20] В.Ф. Гантмахер. Электроны в неупорядоченных средах. ФИЗМАТЛИТ, М. (2005). 232 с. 